\section{DÓLAR, VINO, LEGO Y OTRAS HISTORIAS DEL AJUSTE MACROECONOMICO.}

Por Carlos J. García. Académico FEN UAH. PhD Universidad de California, USA.

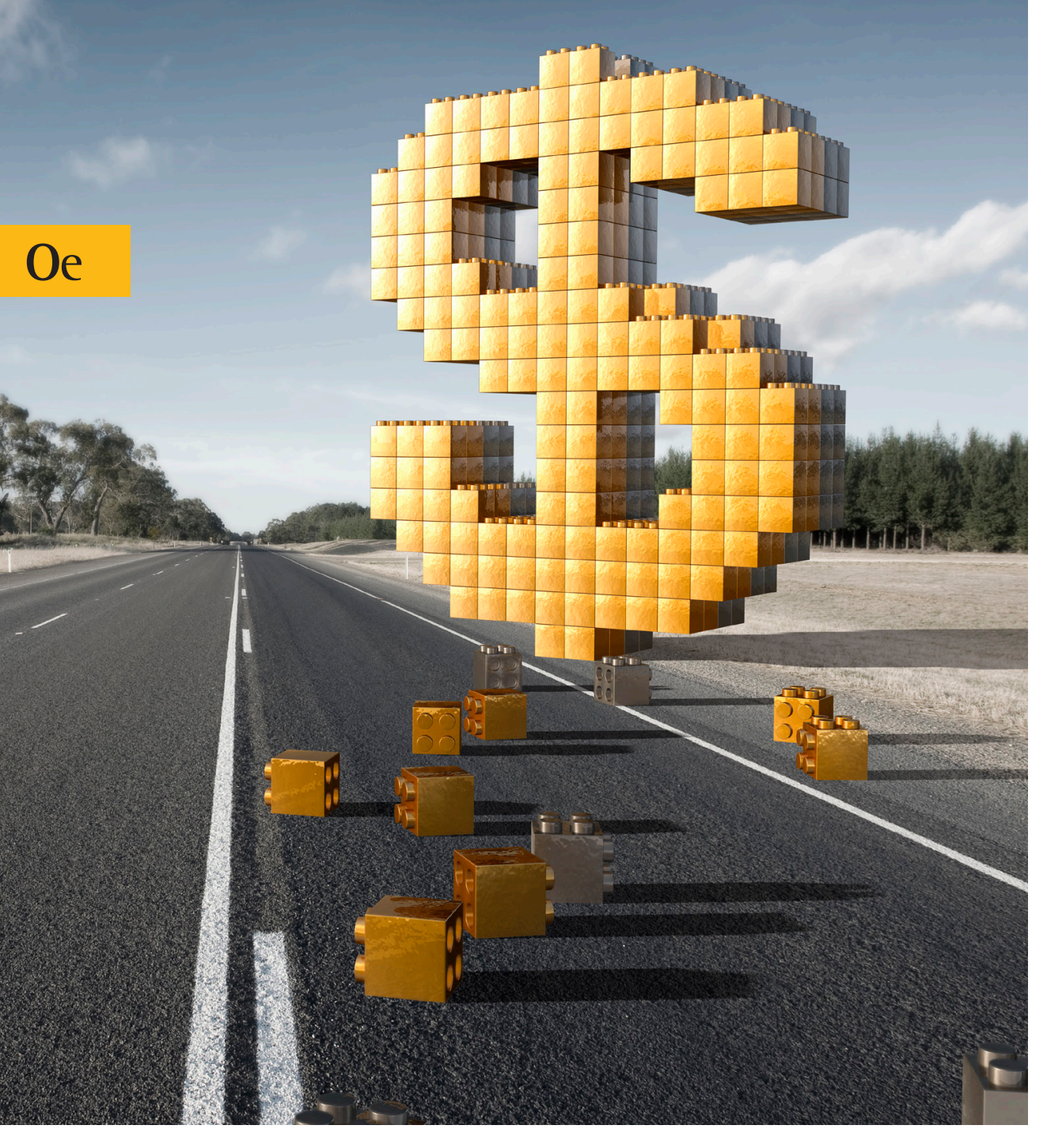

¿Es bueno un dólar alto para la economía chilena? La respuesta depende de varios elementos.

Primero, en un régimen de tipo de cambio fiexible como es el adoptado por el Banco de cambio son una forma de ajuste macroeconómico para la economía. En efecto, si la economía pasa por malos tiempos, es decir, bajo crecimiento, el aumento del tipo de cambio o depreciación del peso permitestimular las exportaciones y con ello la - cuneración Como algunos recordaran, resto fue lo que exactamente ocurrio después de la crisis de la deuda externa de 1982, luego en la crisis asiática de 1997, y la mini recesiön en 2009.

Segundo, para que la historia anterior uncione hay un mecanismo que debe dear de funcionar: los precios de la economía deben moverse lentamente, por ejemplo, aquellos medidos por el IPC. De esta forma al subir el tipo de cambio por sobre los precios (el IPC), el mercado internacional es más atractivo para un productor que cada dólar que se vende, por ejemplo, por
cadóntico. En otras palabra una botella de vino chileno en un super-
und mercado de California, Los Ángeles, en Estados Unidos produce más pesos que esa misma botella de vino vendido en un supermercado en Nuñoa o en Puerto Montt, botella de buen vino chileno al supermercado de California, para el bienestar de todos los californianos.

Producir más para los mercados externos
produce un ciclo positivo. Las empresas ex- portadoras contratan más personas, piden más créditos y la inversión del sector se es-
timula. Sin embargo, no todo es tan bueno como parece, los bienes importados suben de precios, por eso, los automóviles, los electrodomésticos, la ropa de China, incluso los LEGOS de mis hijos se vuelven màs caros! El dólar al subir por ejemplo desde 500 pesos por dólar a 700 pesos por

$Y$ si es as'i isuben el precio de los

GOS y otros productos en un $40 \%$ ? necesariamente, esa es una decisión de los importadores. En efecto, si un importador decide vender los LEGOS un $40 \%$ más caro, puede que no venda tanto como antes. Claramente comprar un LEGO a un 40\% más es una decisión mia, y en particular, de mi presupuest (no de mis hijos que quieren aumentar su colección!). Al conocer el importador que muchos padres no demandarán más LE$G O S$, puede decidir reducir sus ganancias y aumentar el precio de los LEGOS en, por los padres un aumento de $10 \%$ toun razonab pero lo que es importante que el aumento del délar no se traspaso completamente al precio del juguete. Tercero, si el traspaso del tipo de cambio es bajo, entonces el Banco Central de Chile no necesariamente subirá su tasa de interés para frenar la inflación. En otras palabras, y volviendo al ejemplo del LEGO el Banco Central no deberá subir la tasa de interes para que los padres no pidan un crédito 0 abulten su linea de crédito para comprar el nuevo LEGO de la saga de Stor War o Friends. En caso contrario, los precios de los bienes importados presionaran al te y el Banco Central para mala suerte tergar su compra e inventar abuna historia tan increible como exigir un promedo siete a fin de curso para obtener su regalo. Sin embargo, todas las historias anteriores se complican si los importadores tienen expectativas que el aumento del tipo de cambio continuará. imposible parar el aumento, por ejemplo, del precio de los LEGOS, y con esto se producira el temido traspaso precio no solo de los bienes de consumo, sino que el precio de todos los insumos importados subirán. En este caso, el Banco Central debera subir complican

¿Por qué? El aumento de la tasa de interés presiona para que los extranjeros traigan chilenos para obtener una mejor rentabilidad. Pensemos en las familias americanas, japonesas, europeas y de otros paises que aprovechando tasas de interés más altas en Chile, mandan sus dólares a ver si con esta especulación financiera pueden juntar más dólares y a su vez comprar por ejemplo los deseados LEGOS a sus hijos. El aumento en a oferta de dólares sin embargo, presiona a Sin el precio del dolar.

pin embargo, necesitamos un dólar alto para exportar nuestros vinos a precios competitivos a los supermercados califorcostos en la producción del vino un candidato es el costo del trabajo y de la tierra. Los precios de estos factores de producción deben caer para que nuestros exportadores puedan ofrecer por ejemplo, a los supermercados californianos vino chileno barato. En caso que los salarios (sueldos) y el precio de otros insumos no caigan rápidamente (en términos reales), la menor demanda port trabajadores y tierra cae. En ese punto, comienza a crecer el desempleo y muchos de los padres no solo no podrán comprar mas Les varios paises simultáneamente necesitan hacer el mismo ajuste macroeconómico de . Además, es probable que las familias de Calfornia, producto que su economía no salarios, dejen de demandar el buen vino chileno por barato que sea. Este fenómeno no solo puede ocurrir en los Estados Unidos sino también en Europa, Japón, etc. La revista The Economist ha bautizado este fenomeno como un periodo de "baja inflacion": las familias de todo el mundo frente a gincertidumbre prefieren ahoriar envez do gastar: mal por el vino chileno y por mucho orros productos exportados por economias Una hes hacia el mundo desarrollado. Una buena moticia es que uno de los cio del petróleo. Por lo que los costos de levar vino a los supermercados califor nianos debieran caer y con esto, los costos de producción de muchos otros productos suavizaran la necesidad de reducciones dicionales de sueldos y salarios reales. Desde esta perspectiva las familias que a

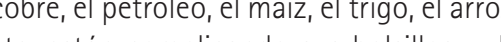
com solsillos, y compra de LEGOS y muchos otros producmundial agarre vuelo nuevamente.

ividad de la economía chilen s vital para impulsar el ajuste que se avebio suba, aunque con eso se deba aceptar algo de inflación adicional y se postergue por un par de años más esa meta. Por contrario, la economia deberá hacer ajustes dolorosos en términos de empleo. ner el gasto en áreas claves, hasta que la tornenta amengue. En caso contrario no

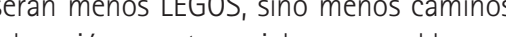
sufín e gasto social en general los que le se retrocederán algunos pasos en esarrollo de nuestro pais.

Dcano: Jorge Rodriguez Gross

e-mail: jrodrigu@uahurtado.cl
fen.uahurtado.cl 